\title{
TRANS3 em Trânsitos (2014)
}

\author{
Richard Augusto Silva ${ }^{1}$
}




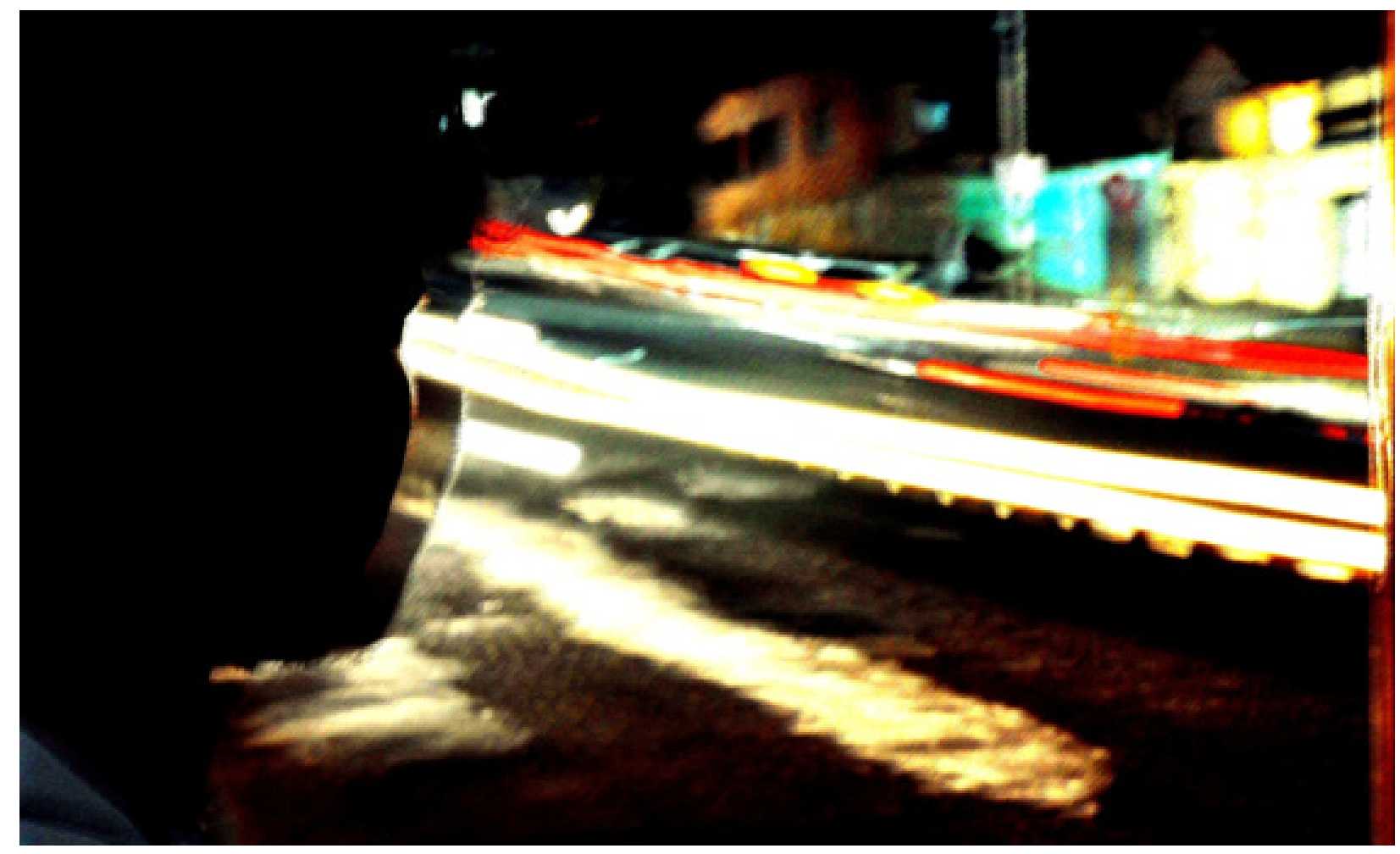

1 TRANS3 em Trânsitos: Série fotográfica do Viaduto José Aielo e a Avenida Duque de Caxias, da cidade de Bauru-SP. Ação TRANS3 em Trânsitos ocorre por meio de uma deriva e suas concatenações entre zonas, tempo, tencionamentos e mobilidade. 

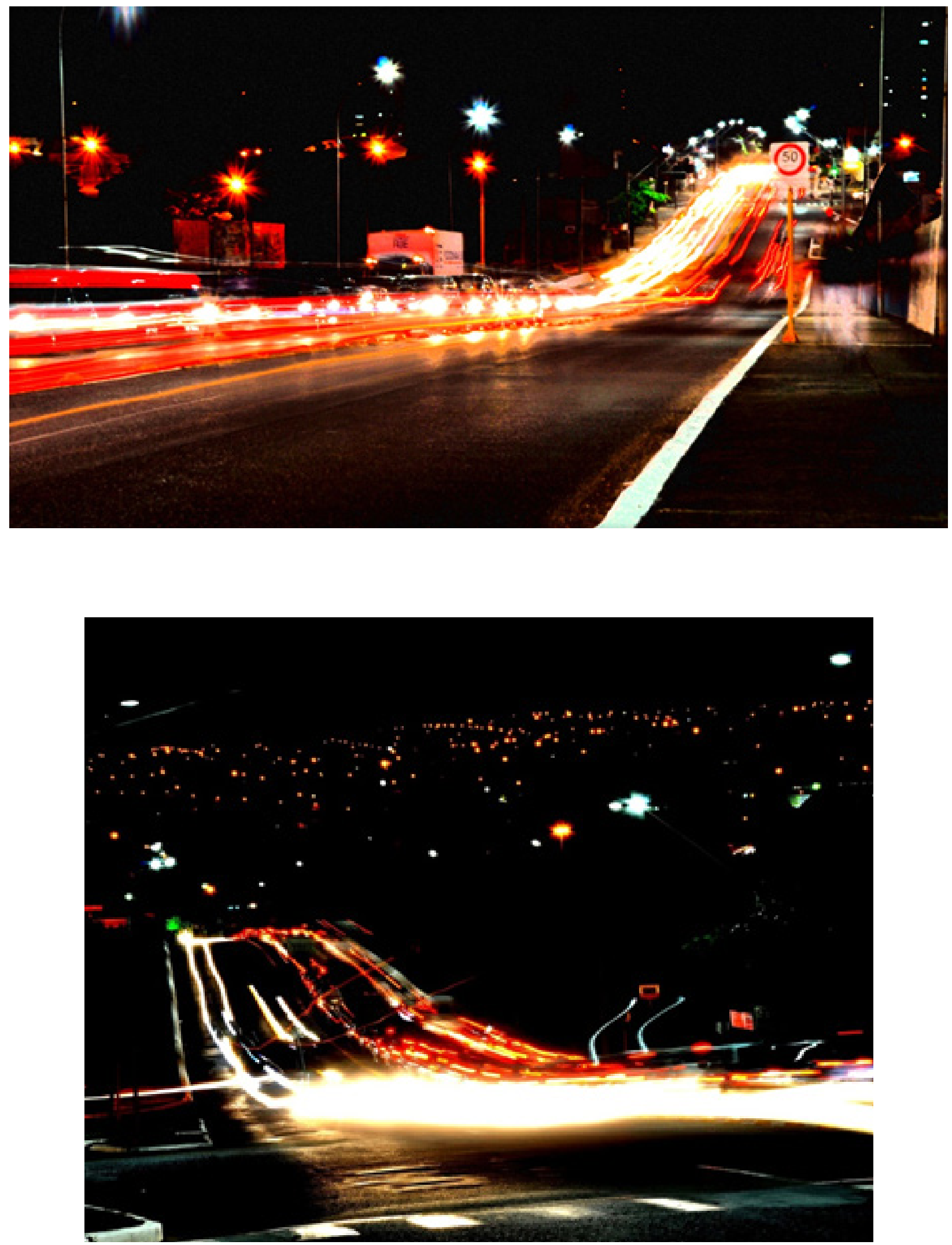

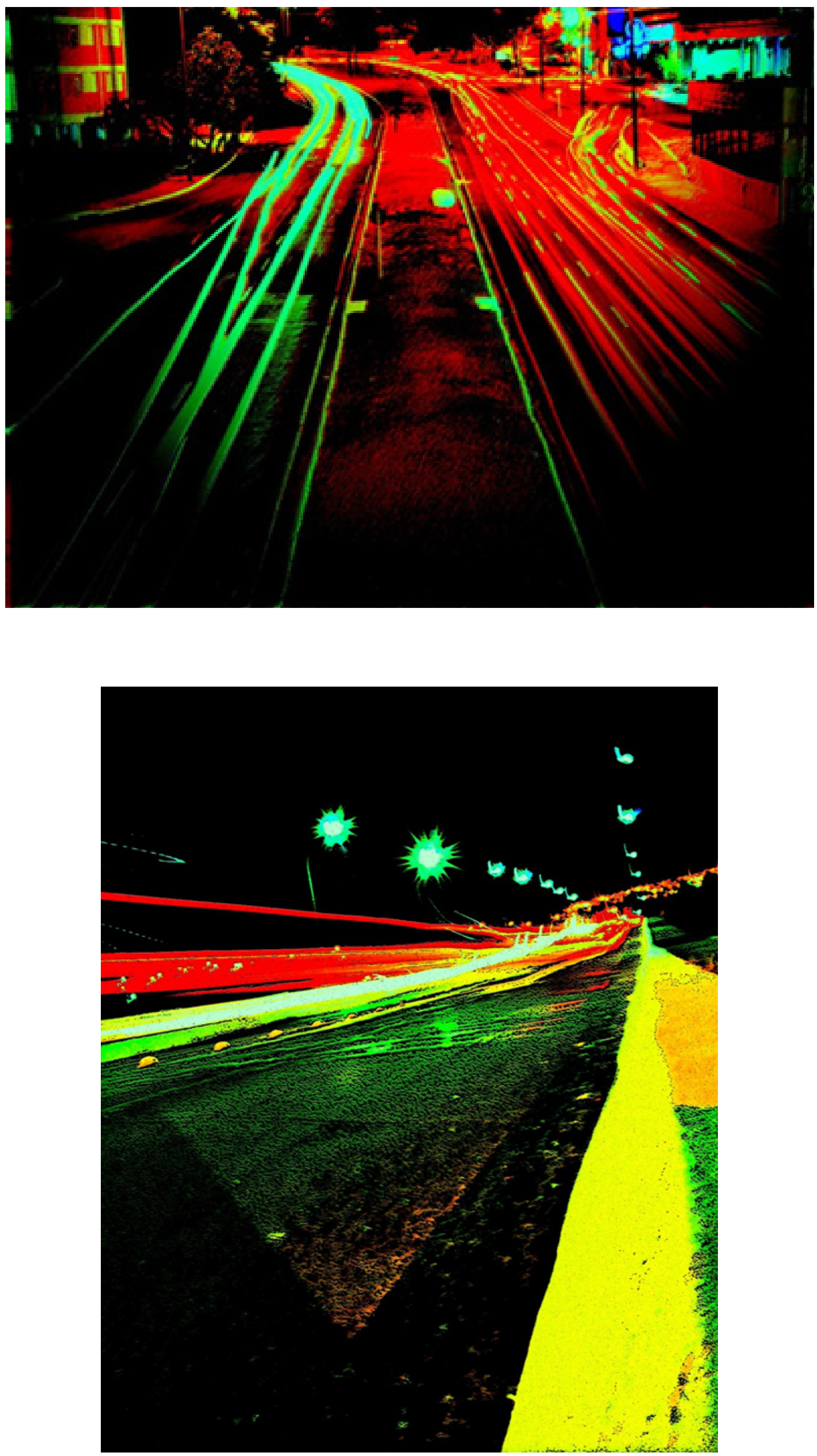